\title{
Utilization of Quarry By-Products for Reduction of Expansion Due to Alkali-Aggregate Reaction
}

\author{
Benjamin J. Mohr ${ }^{1, *}$, Lindsay B. Bryant ${ }^{2}$ \\ ${ }^{1}$ Department of Civil and Environmental Engineering, Tennessee Technological University, \\ 1020 Stadium Drive, Box 5015, Cookeville, TN 38505-0001, USA \\ ${ }^{2}$ Smith Seckman Reid, Inc., 2995 Sidco Drive, Nashville, TN 37204, USA \\ *Corresponding author. Email: bmohr@tntech.edu; Phone: 931-372-3454; Fax: 931-372-6239
}

\begin{abstract}
The replacement of normal fine aggregate with high fines limestone screenings is a technique to reduce waste from crushed stone operations, while potentially improving the durability and performance of concrete. The main objective of this research is to evaluate varying percentages of high fines limestone screenings as a partial weight replacement of reactive fine aggregate (similar to limestone sweetening) in mortars to assess reductions in the expansion due to alkaliaggregate reaction (ASTM C 227, ASTM C 1260, and modified ASTM C 1105). Fresh and hardened properties have been evaluated to assess the effects of limestone screenings on performance criteria. Environmental scanning electron microscopy (ESEM) was performed to visually observe and confirm alkali-aggregate reaction products and associated damage. From the physical testing and microstructural analysis, it was found that $50 \%$ or more of limestone screenings significantly reduce expansions due to alkali-aggregate reaction, attributed to the preference for monocarbonate formation in the presence of limestone and/or reactive silica dilution. Replacements less than 50\% did not significantly reduce expansion.
\end{abstract}

Keywords: alkali-aggregate reaction; expansion; limestone; screenings; aggregates; microscopy 


\section{Introduction}

During the production of crushed stone, screenings, typically containing nine to fifteen percent fines (i.e., particles passing the \#200 sieve), are produced. It is estimated that these by-products are being produced at a rate of 175 million tons per year in the United States [1]. However, this by-product is typically not allowed as ASTM C 33 specifications are not met due to more than $10 \%$ passing the \#200 sieve. As sustainability concerns rise, there is an emphasis to increase the use of manufactured by-products in concrete mixtures [2]. The replacement of normal fine aggregate with high fines limestone screenings is a potential technique to reduce waste from crushed stone operations without significantly impacting the durability and performance of concrete [3].

Currently, ASTM C 150 [4] and ASTM C 595 [5] allow up to 5 and 15\% limestone, respectively, as long as the remaining prescriptive-based specifications are met. However, there is minimal literature to indicate the effects of limestone powder on ASR-induced expansions, beyond alkalidilution. Some evidence shows that $5 \%$ limestone powder may increase expansions due to ASR [6], though it is stated that limestone likely does not contribute to ASR. Additional research has indicated that limestone powder addition (5 to 15\%) does not consistently alter ASR expansions either way $[7,8]$. Despite the apparent innocuous behavior in the presence of limestone in regards to ASR, thaumasite formation has been raised as a potential concern due to the increased available carbonates [9]. 
In order to utilize limestone screenings (which has a high percentage of fines/powder), the effects of screenings replacement of reactive aggregate should be subject to examination as previous research appears to be limited to up to $15 \%$ limestone powder replacement of portland cement only. Thus, the main objective of this research is to approach the limestone-ASR issue from a different direction and evaluate varying percentages of high fines limestone screenings as a partial weight replacement of reactive fine aggregate in mortars to assess reductions in the expansion due to alkali-aggregate reaction. It is anticipated that screenings will reduce expansion due to substitution (dilution) of reactive components but particular attention will be paid to any deviation from a linear relationship between expansion reduction and aggregate composition.

2. Materials and Methods

\subsection{Materials and mixture proportions}

Cementitious mortars were prepared with a water-to-cement ratio of 0.47 and a fine aggregateto-cement ratio of 2.25. Commercially available ASTM Type I/II portland cement and deionized water (resistivity of $18.2 \mathrm{M} \Omega \cdot \mathrm{m}$ ) were used. Oxide analysis and Bogue potential composition for the cement are listed in Table 1. The equivalent alkali content was increased to $1.25 \%$ for ASTM C 227 testing. Highly reactive cherty sand (Jobe sand from Texas, USA) and high fines limestone screenings were used as fine aggregates. Percentages of reactive Jobe sand were replaced by the screenings on a mass basis. The combined gradations of each aggregate mixture are given in Table 2. No chemical or mineral admixtures were used in this research. Mortars were prepared according to ASTM C 305 [10]. 
2.2 Methods for assessment and analysis

2.2.1 Expansion due to alkali-aggregate reaction

Mortar bars (1x1x11.6") for expansion testing were prepared in triplicate (two sets for a total of six bars) according to ASTM C 1260 [11] and ASTM C 227 [12]. Based on the initial results, follow up testing was performed in triplicate (one set) according to a modified ASTM C 1105 [13]. All samples were demolded 24 hours after casting.

For ASTM C 1260 testing, samples were subsequently stored in deionized water at $80 \pm 2{ }^{\circ} \mathrm{C}$ for an additional 24 hours after demolding. After removal from the hot water curing, initial length measurements were taken and specimens were subsequently stored in a $1 \mathrm{~N} \mathrm{NaOH}$ solution at $80 \pm 2{ }^{\circ} \mathrm{C}$ for the remainder of the testing. Measurements were taken periodically, up to 28 days of exposure to the alkali solution.

For ASTM C 227 testing (cement equivalent alkali content increased to $1.25 \%$ ), samples were stored at $38 \pm 2{ }^{\circ} \mathrm{C}$ over water in a sealed container. For modified ASTM C 1105 testing, samples were stored at $23 \pm 2{ }^{\circ} \mathrm{C}$ and $95 \pm 3 \% \mathrm{RH}$ in an environmental chamber. Exposure conditions were replicated per ASTM C 1105, but mortar bars were used instead of concrete. Initial length 
measurements were taken upon demolding. Measurements were taken periodically, up to 18 and 12 months, respectively.

\subsubsection{Environmental scanning electron microscopy (ESEM)}

Samples for ESEM backscattered electron imaging were prepared by drying at $105^{\circ} \mathrm{C}$ for 1 hour. Epoxy impregnation was accomplished using a Buehler vacuum impregnation system and EPOTHIN epoxy. Potted samples were polished using an automatic Buehler VECTOR variable speed grinder-polisher with sequential grit sizes of 240, 320, 400, and 600 for 2 minutes each, or until all scratches from the previous step were removed. Final polishing was accomplished with 5 and $1 \mu \mathrm{m}$ diamond aerosol sprays. Samples were cleaned with ethanol after each polishing step. Microstructural observations were conducted on a FEI Quanta 200 ESEM in a gaseous (water vapor) environment. Samples were imaged at $20.0 \mathrm{kV}$ and a water vapor pressure of 0.45 Torr $(60 \mathrm{~Pa})$ in backscattered electron mode.

\section{Results and Discussion}

In this research, high fines limestone screenings replaced a portion of ASTM C 33 compliant highly reactive fine aggregate for improved sustainability. The relative effects on alkaliaggregate expansion were assessed. ESEM was also performed to observe the reaction products formed.

\subsection{Physical Testing}


Expansion of mortars containing screenings was evaluated via ASTM C 227 (Figure 1) and ASTM C 1260 (Figure 2). The control (0\% screenings) sample exhibited an expansion of $0.743 \pm 0.009 \%$ at 28 days of ASTM C 1260 exposure. The replacement of $10 \%, 30 \%, 50 \%$, and $100 \%$ natural sand with limestone screenings reduced ASTM C 1260 expansion by 15.5\%, $11.2 \%, 42.2 \%$, and $73.7 \%$, respectively.

The ASTM C 227 control sample showed an expansion of $0.476 \pm 0.048 \%$ at approximately 18 months. Replacements of $10 \%, 30 \%, 50 \%$, and $100 \%$ natural sand with limestone screenings led to decreases in expansion by $10.1 \%, 7.3 \%, 62.6 \%$, and $91.8 \%$, respectively, at approximately 18 months.

The replacement of natural sand with limestone screenings reduced expansion due to alkaliaggregate reaction, generally as expected. When tested according to ASTM C 1260 and ASTM C 227, the $10 \%$ and $30 \%$ replacements reduced expansion by similar amounts. Increased replacement percentage led to additional decreases in expansion, but below the level of the replacement, i.e., the $100 \%$ replacement only decreased expansion by approximately $75 \%$ when tested via ASTM C 1260. Considering the low replacement percentages of reactive aggregate with limestone screenings (i.e., 10 and 30\% replacements), there appears to be a threshold above which replacement of the reactive aggregate is more effective. 
Figure 3 illustrates the percent reduction in expansion at the end of testing (i.e., 28 days for ASTM C 1260 or 18 months for ASTM C 227) as a function of the percent screenings replacement. Errors bars were calculated as the variance of the ratio of two random variables.

At higher replacement percentages (50 and 100\% screenings), reductions in expansion are primarily attributed to a basic reduction in the quantity of reactive aggregate. However, the 10 and $30 \%$ screenings samples only reduced expansion by approximately $10-15 \%$ for both test methods. It is thought that this relatively small reduction in expansion could be due to increased internal restraint from the finer and more angular limestone screenings. Given that the Jobe sand used in this research is highly reactive, there was still sufficient ASR gel forming with $30 \%$ screenings replacement to fill up the available void space and cause the expansions noted. Therefore, above the threshold noted, there is not available reactive aggregate to form enough ASR to completely fill the void space. Thus, expansion still occurred, but not to the extent observed at or below the $30 \%$ screenings threshold.

As expected, the expansions measured for ASTM C 1260 were higher than those for ASTM C 227 due to the severity of the test method [14]. It is interesting to note that while the $100 \%$ screenings samples effectively mitigated expansion according to ASTM C 227 at 18 months, approximately $0.2 \%$ expansion was observed for those samples subjected to ASTM C 1260 at 28 days. It is well known that ASTM C 1260 may produce false positive results due to the high alkaline solution present [14]. Thus, the $0.2 \%$ expansion at 28 days for the control should not immediately be assumed to indicate that the limestone aggregate was reactive. On the other hand, 
ASTM C 227 may underestimate the long-term aggregate reactivity due to leaching of the alkali ions from the mortar bars [14].

While the screenings provided were marketed as non-dolomitic limestone, it appeared that some alkali-carbonate reaction may have occurred under the severe conditions of ASTM C 1260. To evaluate this hypothesis, additional samples were prepared according to a modified ASTM C 1105 (Figure 4). Though some variation exists due to difficulties maintaining a constant 95\% $\mathrm{RH}$, it can be seen that the $100 \%$ screenings sample did not exhibit any observable expansion up to 12 months. As such, alkali-carbonate reaction does not seem to be a major factor with the limestone screenings used in this research although small quantities of dolomite in the limestone may prevent complete mitigation at $100 \%$ replacement. Further research is suggested to confirm this finding.

By-product screenings appear to act as a relatively innocuous aggregate compared to reactive siliceous aggregates. In terms of the reduction of expansion due to ASR, the replacement of reactive aggregates with by-product screenings, even at low replacement percentages, can be a viable method to reduce ASR induced expansions. Though 100\% screenings does not appear to completely eliminate alkali-aggregate expansions, it has the potential to reduce those expansions by $75-95 \%$, dependent upon exposure conditions. Additional research should be followed up using concretes to assess mixes more indicative of field performance.

\subsection{Microstructural analysis}


Environmental scanning electron microscopy (ESEM) was performed to visually observe and confirm alkali-aggregate reaction products and associated damage. Figure 5 presents representative micrographs of the control ( $0 \%$ screenings), $50 \%$ screenings, and $100 \%$ screenings samples subjected to 28 days of exposure according to ASTM C 1260. As expected, the control sample showed significant cracking (Figure 5), which was filled with an amorphous gel, confirmed via EDS to be alkali-silica gel. Also observed was debonding of the aggregate from the paste around the interfacial transition zone, which typically contains ASR gel as well. Gel was also apparent in voids.

In Figure 6a (50\% screenings), interfacial transition zone cracking and debonding was also observed, but only around the siliceous aggregates (upper right in Figure 6a). Little if any interfacial transition zone cracking was observed with the carbonate aggregate (limestone screenings - bottom left in Figure 6a), except in cases where the cracks appeared to originate from the siliceous aggregates. Also of interest is the observation of ettringite formation around the carbonate aggregate. It has been shown that ettringite may not convert to monsulfate in the presence of limestone, instead allowing for the formation of monocarbonate (which is more stable than monosulfate) [15-18]. Thus, it is anticipated that the increased sulfate concentrations allow for precipitation of ettringite in the interfacial transition zone. This was observed in several instances, but did not appear to initiate any cracking in the samples investigated. Ettringite was not observed around any siliceous aggregates and only around some carbonate aggregates. 
With the $100 \%$ screenings samples, no alkali-silica gel was observed. Small microcracks were apparent, as seen in Figure 6b. None of the microcracks appeared to contain any gel-like product or ettringite. However, ettringite was observed in clusters within the paste and air voids. Further research is necessary to determine the mechanisms of ettringite formation in these samples as they were not heat cured. This ettringite formation (versus monosulfate) could also be a contributing factor to the apparent expansions observed in the 100\% screenings samples [19-22].

\section{Conclusions}

In this research, high fines limestone screenings replaced a portion of highly reactive fine aggregate for improved sustainability. The effects on alkali-aggregate expansion (ASTM C 1260, ASTM C 227, and a modified ASTM C 1105) were assessed. ESEM was also performed

to observe the reaction products formed. From the physical testing and microstructural analysis, the following conclusions may be drawn:

- In this research, replacement of highly reactive siliceous aggregate with $50 \%$ or more of high fines limestone screenings proved effective. Since screenings are readily available in most locations due to crushed stone operations, they may be a suitable replacement of siliceous aggregates when ASR is of concern.

- Limestone screenings at replacement percentages of $30 \%$ and below do not appear to effectively mitigate expansion. It is believed that due to the high reactivity of siliceous aggregate used, there was still sufficient ASR gel formation to cause cracking and expansion. Less reactive aggregates may behave differently and have a lower threshold. 
- At replacement percentages of $50 \%$ or more, limestone screenings appeared to mitigate expansion as a function of replacement percent. At $100 \%$ replacement, minor expansions were still noted, but it is unclear whether this was due to alkali-carbonate reaction or simply the severity of the ASTM C 1260 test. It is also possible that ettringite formation contributes to the apparent expansion.

- Microstructural observations revealed alkali-silica gel within the interfacial transition zone of siliceous aggregates, while the presence of ettringite was detected in samples containing carbonate aggregates. Monocarbonate formation in the presence of limestone likely prevents ettringite conversion to monosulfate.

\section{Acknowledgements}

The authors would like to acknowledge the National Science Foundation (CMMI-1030209) for their financial support. Any opinions, findings, and conclusions or recommendations expressed in this material are those of the authors and do not necessarily reflect the views of the sponsors. Special thanks to Dr. Daniel Badoe within the Department of Civil and Environmental Engineering at Tennessee Tech University for assistance in statistical analysis (variance calculations) in Figure 3. 
References

[1] Quarry By-Products: Material Description, Turner-Fairbanks Highway Research Center.

[2] Byard B. High fines limestone screenings as fine aggregate for precast portland cement concrete. M.S. Thesis, Tennessee Technological University, Cookeville, TN; 2007.

[3] Crouch LK, Byard B, Self JD. Making precast concrete mixtures more sustainable with byproduct fine aggregate, The National Bridge Conference, PCI Annual Convention, Orlando, FL, October 7, 2008.

[4] ASTM C 150. Standard specification for portland cement. American Society for Testing \& Materials, West Conshohocken, PA; 2012.

[5] ASTM C 595. Standard specification for blended hydraulic cements. American Society for Testing \& Materials, West Conshohocken, PA; 2014.

[6] Hobbs DW. Possible influence of small additions of pfa, gbfa, and limestone flour upon expansion caused by the alkali-silica reaction. Magazine of Concrete Research 1983;35:5558.

[7] Thomas MDA, Cail K, Blair B, Delagrave A, Barcelo L. Equivalent performance with half the clink content using PLC and SCM. 2010 Concrete Sustainability Conference, National Ready Mixed Concrete Association, Tempe, AZ; 2010.

[8] Thomas MDA, Delagrave A, Blair B, Barcelo L. Equivalent durability performance of portland limestone cement. Concrete International 2013:39-45.

[9] Tennis PD, Thomas MDA, Weiss, WJ. State-of-the-art report on use of limestone in cements at levels of up to 15\%. Portland Cement Association R\&D SN3148, 2011. 
[10] ASTM C 305. Standard practice for mechanical mixing of hydraulic cement pastes and mortars of plastic consistency. American Society for Testing \& Materials, West Conshohocken, PA; 2006.

[11] ASTM C 1260. Standard test method for potential alkali reactivity of aggregates (mortarbar method). American Society for Testing \& Materials, West Conshohocken, PA; 2007.

[12] ASTM C 227. Standard test method for potential alkali reactivity of cement-aggregate combinations (mortar-bar method). American Society for Testing \& Materials, West Conshohocken, PA; 2003.

[13] ASTM C 1105. Standard test method for length change of concrete due to alkali-carbonate rock reaction. American Society for Testing \& Materials, West Conshohocken, PA; 2008.

[14] Thomas MDA, Fournier B, Folliard K, Ideker J, Shehata M. Test methods for evaluating preventive measures for controlling expansions due to alkali-silica reaction in concrete. Cement and Concrete Research 2006;36:1842-1856.

[15] De Weerdt K, Ben Haha M, Le Saout G, Kjellsen KO, Justnes H, Lothenbach B. Hydration mechanisms of ternary portland cements containing limestone powder and fly ash. Cement and Concrete Research 2011;41:279-291.

[16] Bensted J. Further hydration investigations involving portland cement and the substitution of limestone for gypsum. World Cement 1983;14:383-392.

[17] Klemm W, Adams L. An investigation on the formation of carboalumninate. ASTM Special Technical Publication 1064, Eds. Klieger P, Hotton, D, 1990.

[18] Matschei T, Glasser FP. Temperature dependence, 0 to $40{ }^{\circ} \mathrm{C}$, of the mineralogy of portland cement paste in the presence of calcium carbonate. Cement and Concrete Research 2010;40:763-777. 
[19] Kuzel HJ, Pollmann H. Hydration of $\mathrm{C} 3 \mathrm{~A}$ in the presence of $\mathrm{Ca}(\mathrm{OH})_{2}, \mathrm{CaSO}_{4} \cdot 2 \mathrm{H}_{2} \mathrm{O}$ and $\mathrm{CaCO}_{3}$. Cement and Concrete Research 1991;21:885-895.

[20] Hoshino S, Yamada K, Hirao H. XRD/Reitveld analysis of the hydration and strength development of slag and limestone blended cement. Journal of Advanced Concrete Technology 2006;4:357-367

[21] Matschei T, Lothenbach B, Glasser FP. The role of calcium carbonate in cement hydration. Cement and Concrete Research 2007;37:551-558.

[22] Lothenbach B, Le Saout G, Gallucci E, Scrivener K. Influence of limestone on the hydration of portland cements. Cement and Concrete Research 2008;38:848-860. 
List of Tables and Figures

Table 1. Oxide analysis and Bogue potential composition of cement used in this research.

Table 2. Sieve analysis of fine aggregate. Note: 10, 30, 50, and 100\% represent percentage of screenings replacement.

Figure 1. Expansion of mortar bars tested per ASTM C 227.

Figure 2. Expansion of mortar bars tested per ASTM C 1260

Figure 3. Expansion reduction at end of testing (ASTM C 227 and ASTM C 1260) versus

percent limestone screenings replacement of reactive aggregate

Figure 4. Expansion of mortar bars tested per a modified ASTM C 1105.

Figure 5. ESEM BSE micrographs of control ( $0 \%$ screenings) mortar samples.

Figure 6. ESEM BSE micrographs. (a) 50\% screenings mortars. Note: Siliceous aggregate in upper right; carbonate aggregate in lower left. (b) 100\% screenings mortars. 
Table 1

\begin{tabular}{|l|l|}
\hline Oxide & $\begin{array}{l}\text { Type } \mathrm{I} / \mathrm{II} \\
\text { portland } \\
\text { cement }\end{array}$ \\
\hline $\mathrm{SiO}_{2}$ & 19.70 \\
\hline $\mathrm{Al}_{2} \mathrm{O}_{3}$ & 4.33 \\
\hline $\mathrm{Fe}_{2} \mathrm{O}_{3}$ & 3.66 \\
\hline $\mathrm{CaO}$ & 63.41 \\
\hline $\mathrm{MgO}$ & 3.30 \\
\hline $\mathrm{Na}_{2} \mathrm{O}$ & 0.07 \\
\hline $\mathrm{K}_{2} \mathrm{O}$ & 0.68 \\
\hline $\mathrm{TiO}_{2}$ & 0.23 \\
\hline $\mathrm{P}_{2} \mathrm{O}_{5}$ & 0.06 \\
\hline $\mathrm{SrO}_{2}$ & 0.05 \\
\hline $\mathrm{SO}_{3}$ & 3.11 \\
\hline $\mathrm{LOI}$ & 1.40 \\
\hline $\mathrm{C}_{3} \mathrm{~S}$ & 65.18 \\
\hline $\mathrm{C}_{2} \mathrm{~S}$ & 7.65 \\
\hline $\mathrm{C}_{3} \mathrm{~A}$ & 5.29 \\
\hline $\mathrm{C}_{4} \mathrm{AF}$ & 11.12 \\
\hline
\end{tabular}




\begin{tabular}{|c|c|c|c|c|c|c|c|c|}
\hline \multirow{2}{*}{$\begin{array}{c}\text { Sieve } \\
\text { Number }\end{array}$} & $\begin{array}{c}\text { Sieve } \\
\text { Opening } \\
\end{array}$ & \multicolumn{7}{|c|}{ Percent Passing } \\
\cline { 3 - 9 } & $\begin{array}{c}\text { ASTM } \\
\text { C33 min }\end{array}$ & $\begin{array}{c}\text { ASTM } \\
\text { C33 max }\end{array}$ & Control & $10 \%$ & $30 \%$ & $50 \%$ & $100 \%$ \\
\hline $3 / 8 "$ & 9.5 & 100 & 100 & 100 & 100 & 100 & 100 & 100 \\
\hline$\# 4$ & 4.75 & 95 & 100 & 95.3 & 95.3 & 95.4 & 95.4 & 95.6 \\
\hline$\# 8$ & 2.36 & 80 & 100 & 81.9 & 80.0 & 76.3 & 72.6 & 63.3 \\
\hline$\# 16$ & 1.18 & 50 & 85 & 73.4 & 69.8 & 62.7 & 55.6 & 37.9 \\
\hline$\# 30$ & 0.6 & 25 & 60 & 53.7 & 50.9 & 45.2 & 39.5 & 25.4 \\
\hline$\# 50$ & 0.3 & 5 & 30 & 12.3 & 12.8 & 14.0 & 15.1 & 17.9 \\
\hline$\# 100$ & 0.15 & 0 & 10 & 1.5 & 2.7 & 5.2 & 7.6 & 13.8 \\
\hline$\# 200$ & 0.075 & 0 & 0 & 0.2 & 1.3 & 3.5 & 5.7 & 11.3 \\
\hline
\end{tabular}




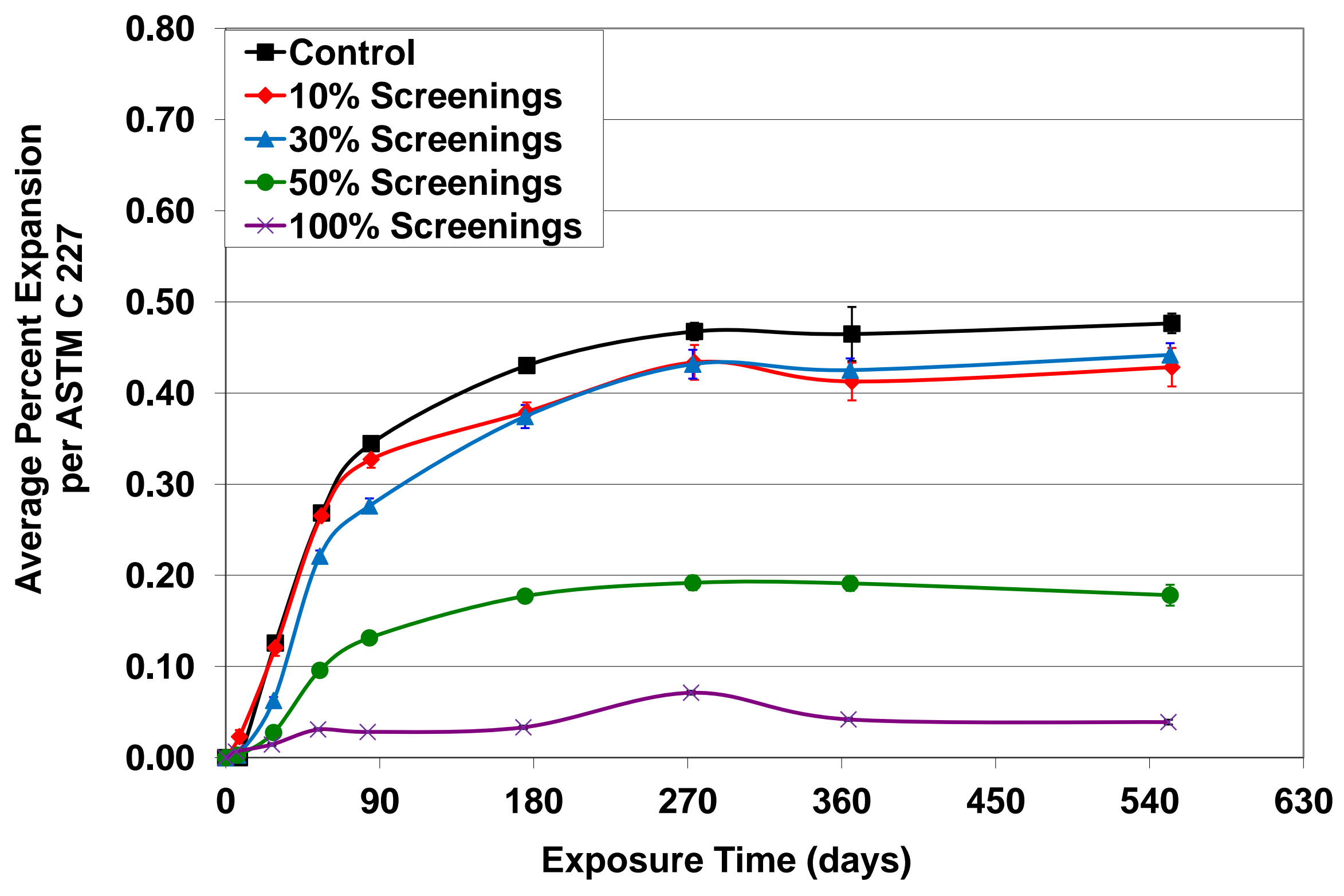




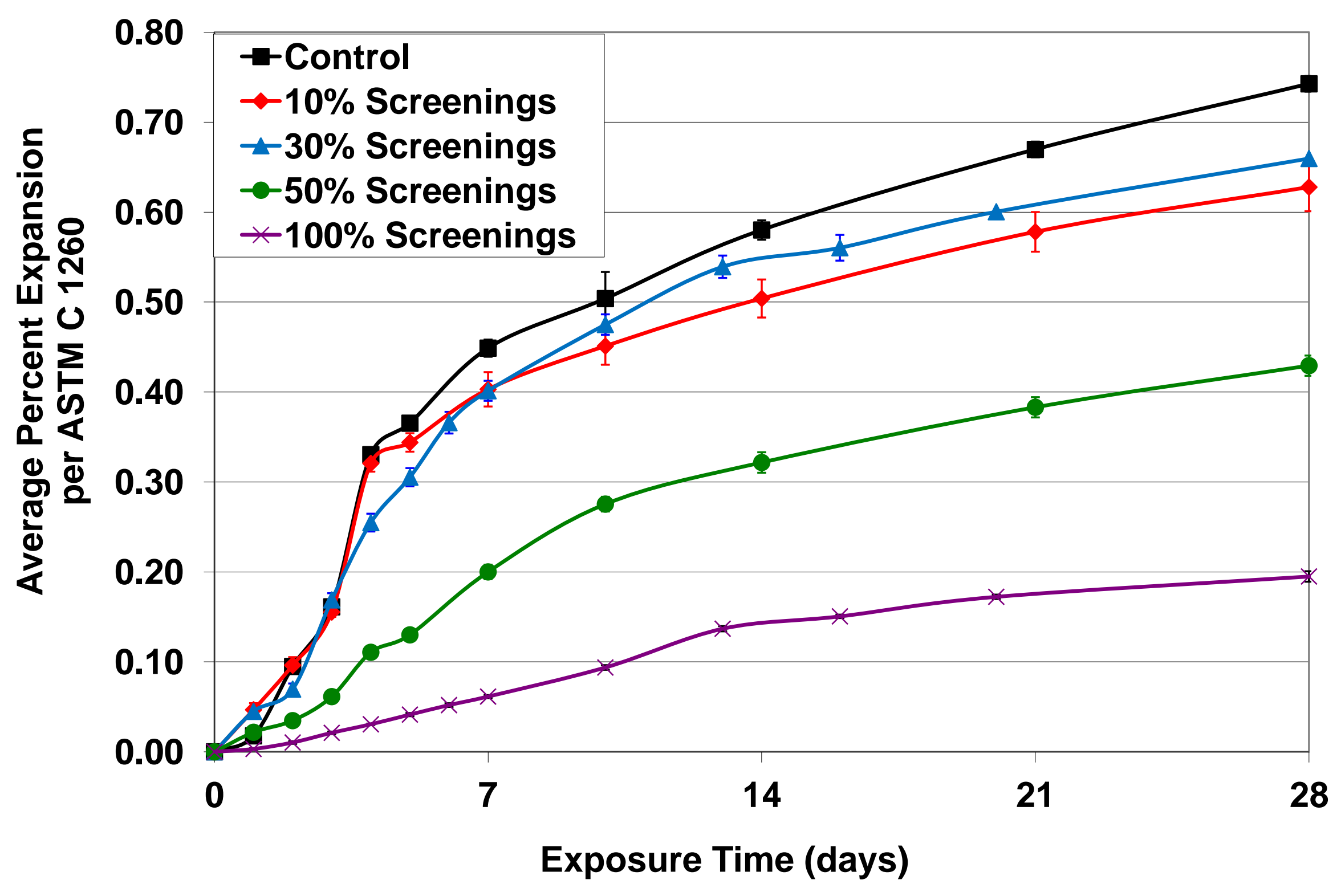




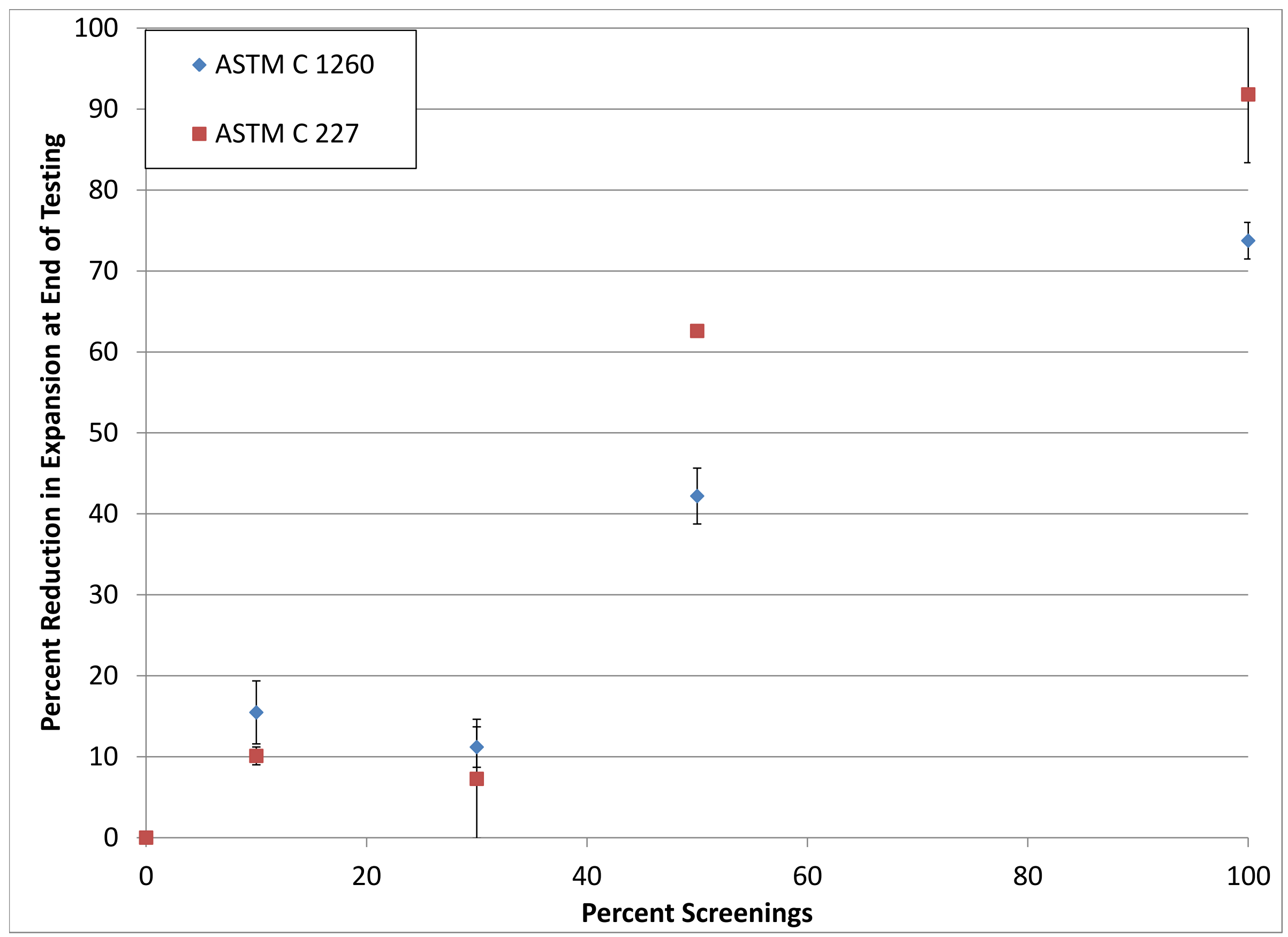




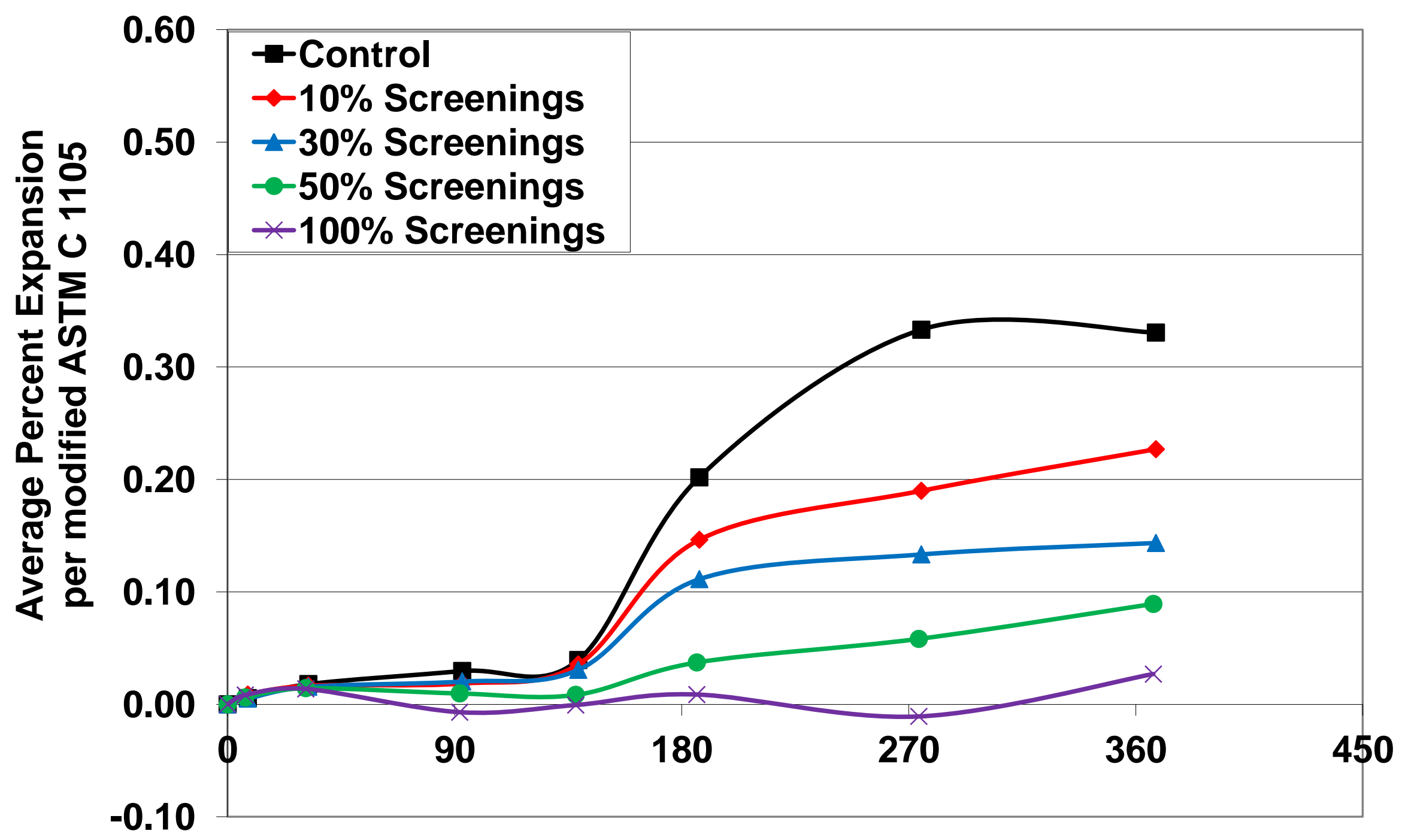

Exposure Time (days) 


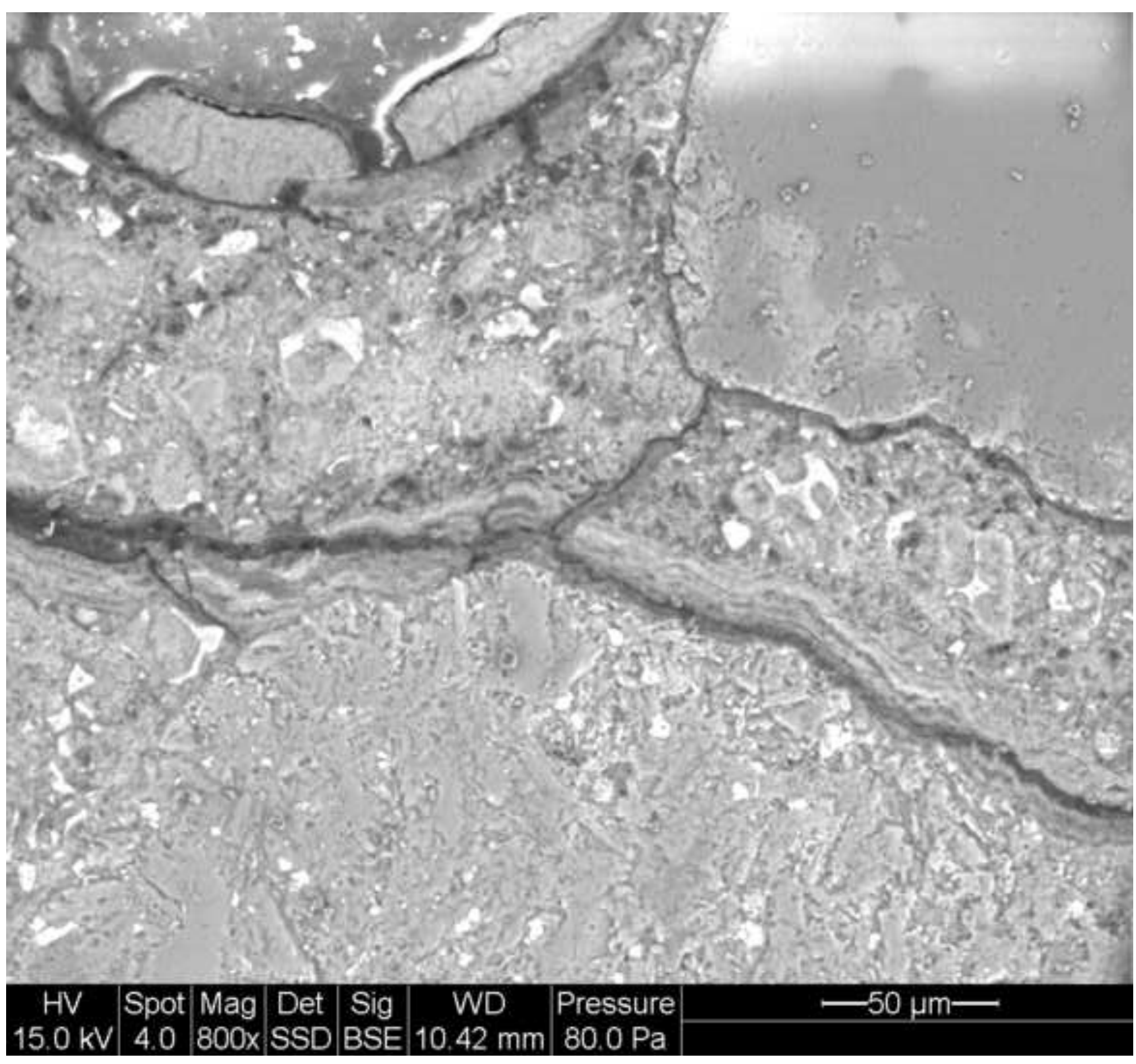




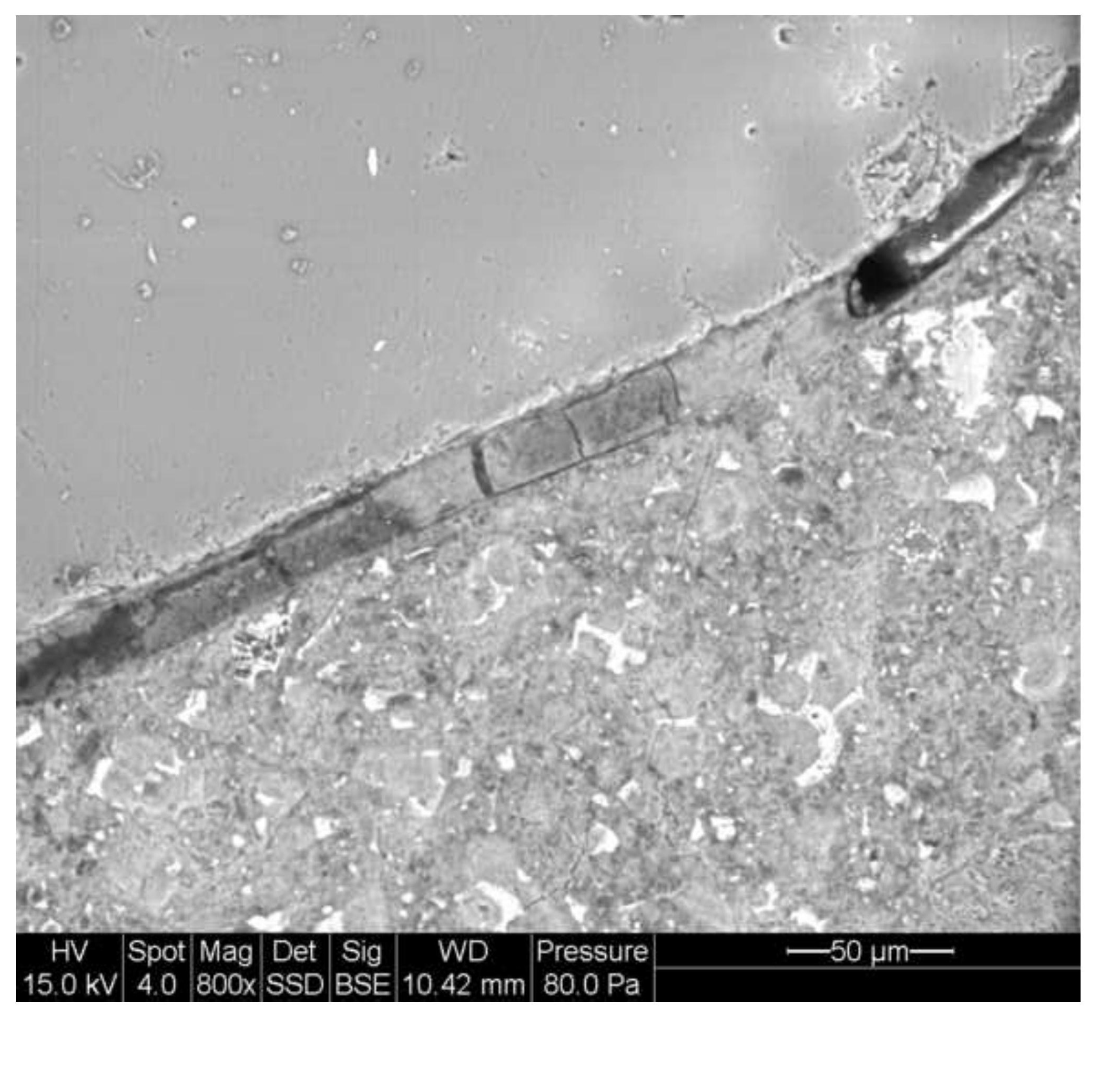

-

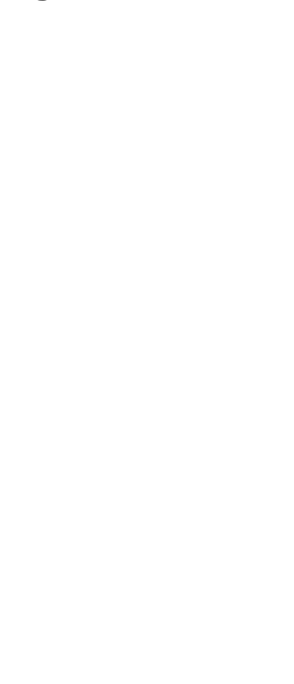

\section{.}
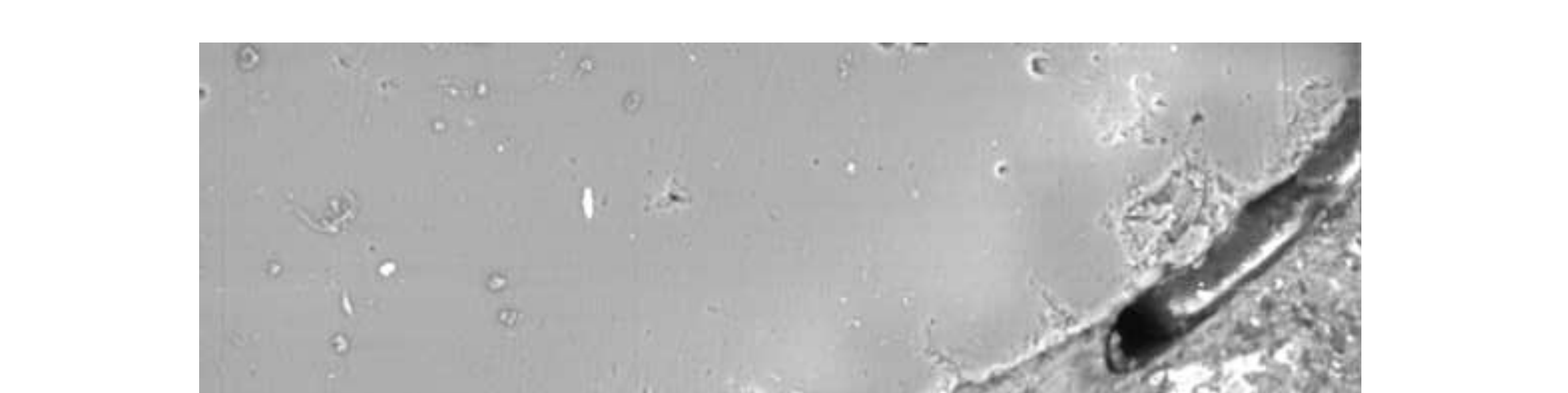

$$
\text { . }
$$$$
\text { . }
$$

$$
\text { . }
$$

$$
\text { . }
$$
.

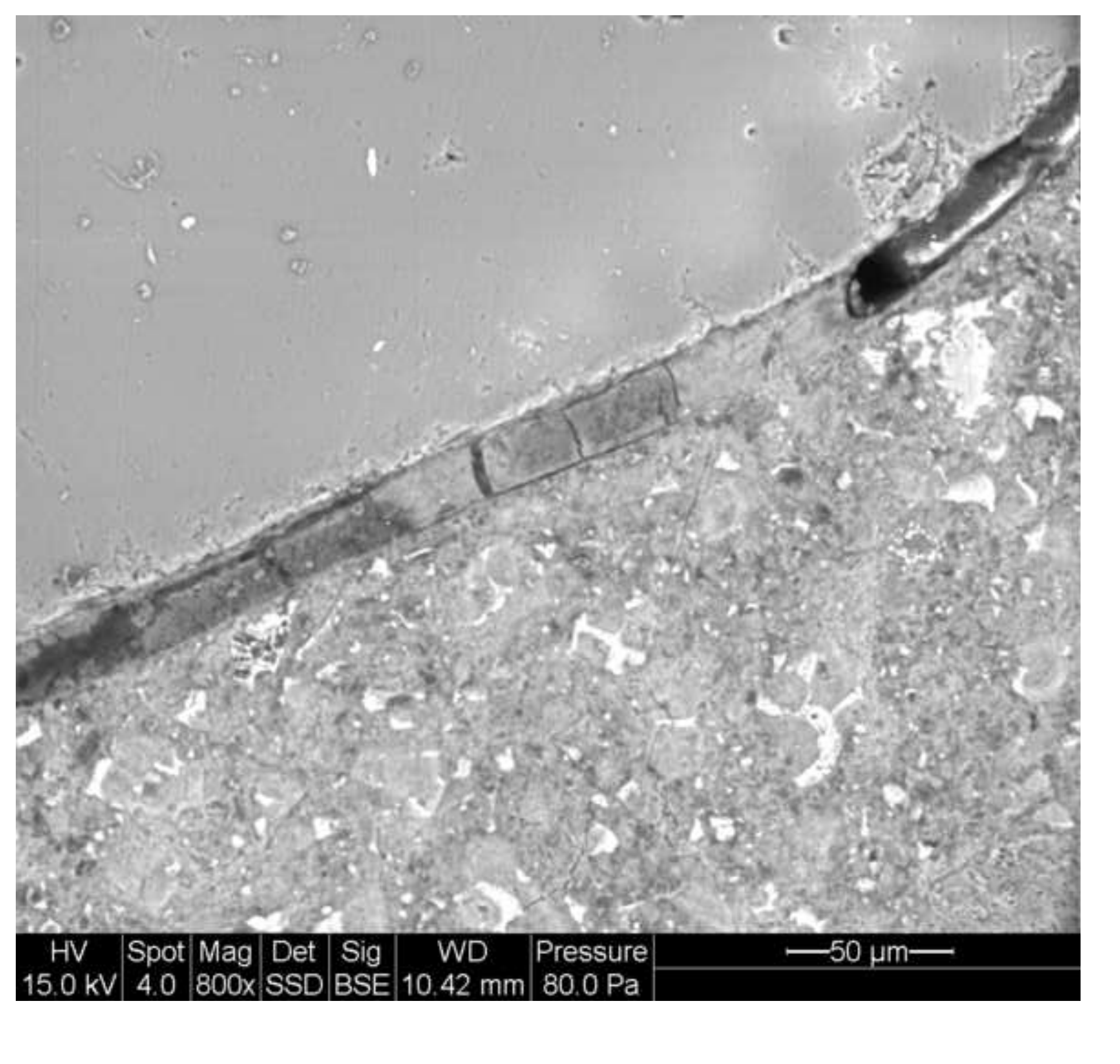

.

.

.

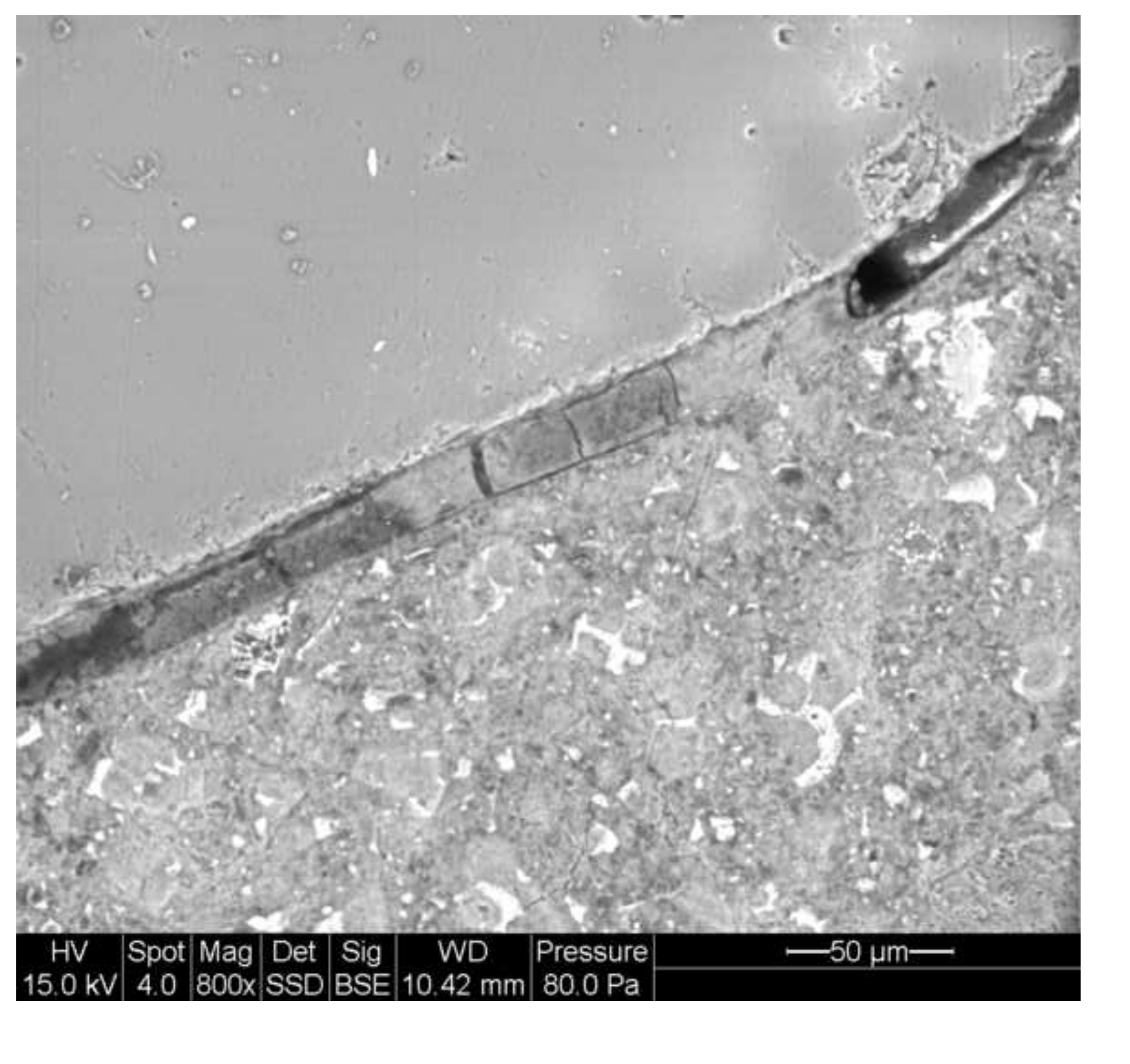




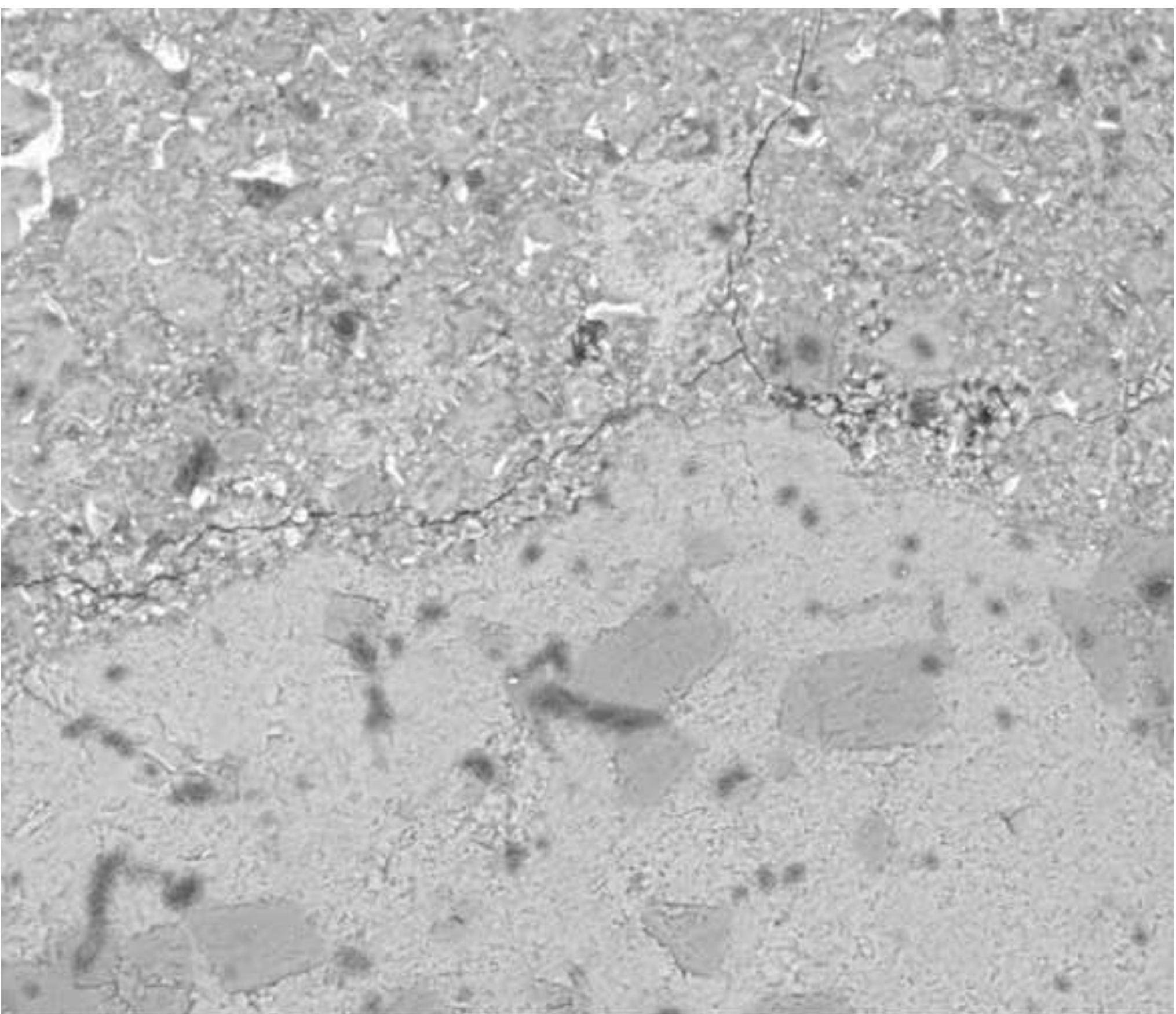

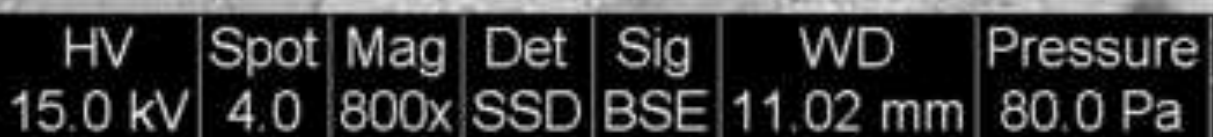

$-50 \mathrm{~mm}-$

15.0 kV 4.0 800x SSD BSE $11.02 \mathrm{~mm} 80.0 \mathrm{~Pa}$ 